\title{
FORMAÇÃO DE PROFESSORES E PRÁTICA DOCENTE: UMA REFLEXÃO À LUZ DO PENSAMENTO CRÍTICO MARXISTA
}

\author{
Lúcia Helena de Brito ${ }^{1}$ \\ Lydyane Maria Pinheiro de Lima ${ }^{2}$ \\ Sirneto Vicente da Silva ${ }^{3}$
}

\begin{abstract}
Resumo:
$\mathrm{O}$ artigo propõe-se a analisar os atuais modelos de formação continuada propostos pelo Estado brasileiro aos professores da rede pública de ensino, no âmbito das políticas educacionais e seus programas de formação. $\mathrm{O}$ intuito é evidenciar os fundamentos que os embasa buscando compreender a concepção de formação proposta e sua relação com as demandas do capital. Orienta-nos a hipótese de que os programas de formação de professor impostos pelo Estado, ao priorizarem o aperfeiçoamento de competências e habilidades destinadas a soluções imediatistas de problemas restritos à prática docente em sala de aula, possuem teor tecnicista e comprometem a compreensão por parte dos professores acerca do amplo contexto no qual está inserida a sua prática docente. Ao efetuarmos estudo bibliográfico sobre o tema e leitura reflexiva das diretrizes que fundamentam os referidos programas verificamos que o quadro conceitual que consubstancia as competências e habilidades propostas como objetivo da formação encontra-se no âmbito da "epistemologia da prática"- formar o professor reflexivo, crítico, a preparar-se para refletir sobre sua prática docente em circunstâncias reais, no momento da ação. Salientamos que a reflexão sobre a prática docente somente pode ser vislumbrada por meio da formação do pensamento crítico. À luz do conceito de crítica em Marx, o ato da reflexão pressupõe um questionamento, que inclui o exercício do pensamento para o entendimento sobre o modo de agir sobre o mundo, e inclui, portanto, intervenções e mudanças. A construção de uma prática emancipatória na escola, mediada pela ação pedagógica, exige o entendimento dos aspectos sociais e históricos nos quais se insere o professor. Inscreve-se na luta por participação efetiva dos sujeitos envolvidos (educadores e educandos) no planejamento e execução dos programas de formação, na luta por uma pedagogia dialógica, uma pedagogia da práxis.
\end{abstract}

Palavras-Chave: Política educacional. Formação de professores. Pensamento crítico-marxista. Prática docente. Emancipação humana.

\section{TEACHER FORMATION AND TEACHING PRACTICE: A REFLEXION ACCORDING TO MARXIST CRITICAL THINKING}

\begin{abstract}
:
The purpose of this article is to analyse the current continuing education models offered by Brazilian State to the public school teachers, within the scope of educational politics and its formation programs. The aim is to highlight the fundamentals that support them in order to understand the conception of this proposed formation and its relation with capital demands. We are guided by the hypothesis that the teacher training programs imposed by the State, when prioritizing the improvement of competences and abilities destined to immediatist solutions of problems restricted to the teaching practice in the classroom, have a technical content and compromise the teachers' understanding of the broad context in which their teaching practice is inserted. After a bibliographic study on the subject and a reflective reading of the guidelines that underlie the mentioned programs we found that the conceptual framework which embodies the competencies and abilities proposed as an objective of formation lies within the scope of the "epistemology of practice" - to train the reflective, critical teacher, to prepare him to reflect on his teaching practice in real circumstances, in the moment of the action. We emphasize that the reflection about the teaching practice can only be glimpsed through the formation of critical thinking. According to

\footnotetext{
${ }^{1}$ Doutora em Sociologia pela Universidade Federal do Ceará/UFC. Professora da Universidade Estadual do Ceará, Campi FAFIDAM/UECE. Colaboradora do MAIE/UECE. E-mail: lhelena.brito@uece.br.

${ }_{2}^{2}$ Mestranda pelo Mestrado Acadêmico em Educação e Ensino - MAIE/UECE.

${ }^{3}$ Mestrando pelo Mestrado Acadêmico em Educação e Ensino - MAIE/UECE.
} 
the concept of criticism in Marx, the act of reflection presupposes a questioning, which includes the exercise of thought for the understanding of how to act on the world, and therefore includes interventions and changes. Building an emancipatory practice in school, mediated by pedagogical action, require the understanding of the social and historical aspects in which the teacher is inserted. It is part of the struggle for effective participation of the subjects involved (educators and learners) in the planning and execution of training programs, in the struggle for a dialogical pedagogy, a pedagogy of praxis.

Key Words: Educational politics. Teacher training. Critical-Marxist thinking. Teaching practice. Human emancipation.

\section{Introdução}

O presente artigo tem como objetivo identificar a teoria do conhecimento predominante nos modelos de formação continuada de professores da rede pública de ensino, a partir dos programas implementados pelo Estado nas escolas de Educação Básica. ${ }^{4}$ Nosso intento é refletir sobre os programas de formação docente observando o modo como atuam no desenvolvimento de estratégias pedagógicas voltadas para o êxito dos alunos em avaliações estandardizadas aplicadas nas instituições escolares.

Ao constatarmos que os programas de formação docente chegam às escolas no contexto das políticas públicas estatais já prontas para serem executadas, inferimos que há grande possibilidade de que essa formação se configure como um ato autoritário, o que compromete o caráter democrático da gestão educacional ao se desconsiderar os sujeitos sociais que constituem o trabalho escolar. Ainda, nesses termos, o espaço político da ação do professor torna-se cada vez mais esvaziado, à medida que não lhes são dadas condições de refletir sobre sua prática. Exige-se do professor a "reflexão na ação", nos termos dos programas de formação continuada. Tomamos como referência o Pacto Nacional pelo Fortalecimento do Ensino Médio (PNEM) ${ }^{5}$ e o Programa de Intervenção Pedagógica em Português e Matemática (SIPPEM) ${ }^{6}$.

Partimos da hipótese de que as circunstâncias em que se realizam essas formações, bem como os instrumentos e conteúdos presentes no programa formativo,

\footnotetext{
${ }^{4}$ A reflexão aqui empreendida tem sua origem na pesquisa, por nós realizada, dos modelos de formação de professor impostos pelo Estado do Ceará, tendo como lócus de observação o município de Russas-CE.

${ }^{5}$ O Pacto Nacional pelo Fortalecimento do Ensino Médio (PNEM), instituído pela Portaria Ministerial n. 1.140, de 02/11/2013, possui como uma de suas ações a Formação Continuada de Professores e Coordenadores do Ensino Médio nas escolas públicas de ensino. Por adesão ao PNEM, a Secretaria de Educação do Estado do Ceará desenvolveu o programa de formação de professores em 2014 e 2015 em todas as escolas estaduais de ensino médio.

${ }^{6}$ O Sistema de Intervenção Pedagógica em Língua Portuguesa e Matemática (SIPPEM), instituído no município de Russas-CE em 2013, com o objetivo de desenvolver um trabalho pedagógico para subsidiar a melhoria da qualidade educacional na rede municipal, tendo como metas principais elevar a proficiência das turmas de $9^{\circ}$ ano do Ensino Fundamental da Prova Brasil e do Sistema Permanente de Avaliação do Estado do Ceará (SPAECE), nas disciplinas de Língua Portuguesa e Matemática (Plano Municipal de Educação - PME, 2015-2025, Russas-CE).
}

\begin{tabular}{|l|l|l|l|l|}
\hline Q Rovista Dialectus & Ano 4 & n. 10 & Janeiro - Julho 2017 & p. 150-168 \\
\hline
\end{tabular}


comprometem a construção de condições para aquisição por parte dos professores da capacidade para a reflexão e reconhecimento do sentido de sua prática docente como práxis pedagógica.

A pedagogia como práxis aponta para a superação da noção de prática como atividade meramente instrumental e utilitária que prescinde da reflexão acerca da dimensão ética, filosófica, teleológica da ação, inibindo a reflexão sobre os fundamentos e intencionalidades da ação humana no mundo. Práxis não é apenas a dimensão prática da relação do homem com a natureza e com os homens, caracterizada pelas possibilidades de manipulação e intencionalidades, aqui a práxis é pensada como a manifestação do homem,

[...] como ser ontocriativo, como ser que cria a realidade (humano-social) e que, portanto, compreende a realidade (humana e não-humana, a realidade na sua totalidade). A praxis do homem não é atividade prática contraposta à teoria; é determinação da existência como elaboração da realidade. (Kosik, 1976, p. 202, grifos do autor).

Assumimos práxis como uma categoria da teoria dialética no âmbito do pensamento crítico em que se apoia o materialismo histórico de Marx, com seu método para conhecer a realidade, exposto na crítica da economia política (Marx, 2016). Nesses termos, toda crítica é a busca racional das determinações mais profundas que constituem a realidade.

A atividade educativa, mediada pela interpretação teórica, permite ao professor compreender sua prática como uma ação transformadora. Nesse sentido, a formação pressupõe um processo de autonomia, posto que fundado na ação transformadora, tem um sentido de emancipação.

Marx (1993) afirma que a emancipação é um ato de liberdade que só se realiza em relação à liberdade do outro, onde cada indivíduo se reconhece em relação à comunidade. A referência da prática emancipatória é a liberdade do homem e da comunidade de homens, é a superação da noção de liberdade individual concebida no seio da sociedade de classes, sob a proteção do Estado de Direito, cujo pilar central é a defesa da propriedade privada como realização da liberdade egoísta, do indivíduo separado da comunidade. De acordo com Marx (1993),

Toda a emancipação constitui uma restituição do mundo humano e das relações humanas ao próprio homem. (...) A emancipação humana só será plena quando o homem (...) tiver reconhecido e organizado as suas próprias forças (forces propres) como forças sociais, de maneira a nunca mais separar

\begin{tabular}{|l|l|l|l|l|}
\hline Rovista Dialectus & Ano 4 & n. 10 & Janeiro - Julho 2017 & p. 150-168 \\
\hline
\end{tabular}


de si esta força social como força política. (Marx, 1993, p. 63, grifos do autor).

Pretende-se aqui esboçar um olhar sobre a realidade da formação de professores a partir da visão crítica com base nos pressupostos da dialética em Marx. O conceito de crítica em Marx nos auxilia a pensar a prática docente no sentido de uma ação pedagógica dialética cuja objetivação se situa no âmbito da emancipação humana, portanto, enquanto práxis pedagógica. Com base no referencial crítico-marxista se pode pensar a formação docente como mediação para a formação do pensamento crítico do professor para além do que objetivam as propostas formativas em curso, no intuito de que os professores desvelem o real contexto de inserção da escola num projeto de classes.

\section{A Prática docente frente aos programas de formação de professores: contradições e limites na construção da práxis pedagógica}

A educação é uma atividade social que, em seu sentido restrito, é sistematizada pela instituição escolar. Assim, a escola objetiva a formação de indivíduos capazes de viver em sociedade a partir da reprodução do conhecimento produzido histórica e socialmente. Dessa forma, a fim de compreender o papel cumprido pela instituição escolar torna-se essencial perceber os fundamentos basilares da sociedade capitalista, posto que a prática docente na escola é melhor compreendida se a consideramos inserida no contexto da relação escola e sociedade.

Como afirma Sousa Júnior (2014), o caráter de universalidade, laicidade, obrigatoriedade e gratuidade da educação pública no Estado democrático moderno aparecem em crise a partir dos anos de 1970 quando as políticas neoliberais iniciam sua corrida para promover condições institucionais de ajustes como demanda do capitalismo em crise. Com a fragilização do controle dos estados nacionais sobre as políticas públicas há sobremaneira a imposição de orientações da política educacional dada por corporações transnacionais claramente comprometidas com o processo de reprodução e acumulação do capital. Nesses termos, a escola básica vem sofrendo com inúmeros projetos formativos cujo objetivo é a formação do indivíduo para às demandas dos tipos de trabalho adequados à nova reestruturação produtiva, em contexto de constantes mudanças nas relações capital-trabalho.

\begin{tabular}{|l|l|l|l|l|}
\hline Q Rovista Dialectus & Ano 4 & n. 10 & Janeiro - Julho 2017 & p. 150-168 \\
\hline
\end{tabular}




\section{Lúcia Helena de Brito/ Lydyane Maria Pinheiro de Lima / Sirneto Vicente da Silva}

Desde o modelo de organização da produção de tradição taylorista/fordista se exigiu da educação escolar a formação do trabalhador para adequar-se ao tipo de organização do trabalho visando maximizar a produtividade e a produção em massa, como se exige, sob nosso contemporâneo modelo toyotista, sob o tom da flexibilização, a formação de competências do indivíduo para um mercado de trabalho cada vez mais diversificado em demandas de produção, consumo, e quadros de trabalho. É necessário atentar que a divisão social do trabalho no âmbito do setor produtivo industrial desdobra-se a outros setores da sociedade e não é diferente na escola. A instituição escolar sob os auspícios do Estado moderno organiza-se com base no modelo capitalista de divisão do trabalho e ao assim estruturar-se fragmenta o trabalho do professor na sua prática docente.

O fato de esta sociedade ser fortemente marcada pela intensa divisão social de classes, fundada sob as bases da propriedade privada e a ideia de liberdade de direitos, possibilita fazermos a relação com as políticas públicas de educação que regem os programas de formação de professores e expressam as intenções do Estado por uma escola que contribua para manutenção de um projeto de classe.

A despeito da larga produção acerca da função social da escola, avistamos um reforço da centralidade da educação como preocupação não somente dos estados nacionais, mas também de órgãos formuladores e financiadores de políticas educacionais para os países periféricos, como o Banco Mundial. Nesse âmbito, a Escola Básica voltou a ocupar uma posição privilegiada no que se refere a definições de perfil do indivíduo que se pretende formar por meio do ensino básico.

Apenas para situar um marco dessa trajetória, a Declaração sobre Educação Para Todos (Declaração de Jomtien em 1990), tornou-se a referência de orientações para as políticas de educação dos países em desenvolvimento. A meta fundante foi pela universalização da alfabetização e do nível básico de educação, uma realidade ainda distante para os países em desenvolvimento. A presença constante do Banco Mundial ${ }^{7}$, do Programa das Nações Unidas para o Desenvolvimento (PNUD), Organização das Nações Unidas para a Educação, a Ciência e a Cultura (UNESCO) nas conferências e fóruns mundiais de educação para formular diretrizes educacionais para esses países demonstra o nível de controle que esses órgãos exercem sobre a política educacional e a concepção de formação a ser seguida.

\footnotetext{
${ }^{7}$ O Grupo Banco Mundial congrega o Banco Internacional para Reconstrução e Desenvolvimento (BIRD) e a Associação Internacional de Desenvolvimento (AID).
}

\begin{tabular}{|l|l|l|l|l|}
\hline Q Rovista Dialectus & Ano 4 & n. 10 & Janeiro - Julho 2017 & p. 150-168 \\
\hline
\end{tabular}


Lúcia Helena de Brito/ Lydyane Maria Pinheiro de Lima / Sirneto Vicente da Silva

Assim entendemos o lugar social do Pacto Nacional pelo Fortalecimento do Ensino Médio (PNEM), como política pública de formação de professores para atender ao novo perfil de docente pautado pelas normas contidas na LDB de 1996 e nas Diretrizes Curriculares Nacionais (DCN), publicadas em 2013. O Parecer CNE/CEB n5, de de 4/12/2011, esclarece que as metas do Plano de Desenvolvimento da Educação (PDE) e o Plano Nacional de Educação (PDE), em adesão ao Plano de Metas Compromisso Todos pela Educação, estabelecem a universalização do ensino médio até 2020, e a elevação das médias do Índice de Desenvolvimento s Educação Básica (IDEB).

Para desvendarmos os pressupostos presentes no PNEM faremos referência as suas origens enquanto política pública de educação. Em 2009 o Ministério da Educação, em parceria com o Banco Interamericano de Desenvolvimento (BID), realizou a pesquisa "Melhores Práticas em Escolas de Ensino Médio no Brasil" com a finalidade de recolher experiências exitosas no ensino médio, tendo em vista sugerir aprimoramento desse nível de ensino ${ }^{8}$. No seu relatório final constam dentre as recomendações o apoio e incentivo para criação de estratégias mais eficientes e mais investimentos no desenvolvimento das capacidades das equipes escolares in loco, considerando os conteúdos em relação as necessidades dos professores e da realidade das escolas.

Em 2009 o MEC lança o Programa de Ensino Médio Inovador (ProEMI) ${ }^{9}$, com o objetivo de apoiar e fortalecer o desenvolvimento de propostas curriculares inovadoras nas escolas de ensino médio não profissional, sob orientação de atender as "expectativas dos estudantes" e as "demandas da sociedade contemporânea".

Dentre os objetivos do ProEMI destacamos:

[...] II. Desenvolver e reestruturar o ensino médio não profissionalizante de forma a combinar formação geral, científica, tecnológica, cultural e conhecimentos técnico-experimentais; III. Promover e estimular a inovação curricular do ensino médio; (...) VI. Promover uma escola média onde os saberes e conhecimentos tenham significado para os estudantes e desenvolvam sua autonomia intelectual (Diário Oficial da União. Seção 1, p. 52. 09 de outubro de 2009).

Consideramos que o PNEM se institui no âmbito do ProEMI, que estabelece como uma das metas reestruturar o ensino médio não profissionalizante, na perspectiva

\footnotetext{
${ }^{8}$ A pesquisa foi realizada nos estados do Acre, Ceará, São Paulo e Paraná. O relatório foi entregue ao MEC em dezembro de 2009 e publicado em abril de 2010.

${ }^{9}$ Portaria n. 971 de 09/10/2009.

\begin{tabular}{|l|l|l|l|l|}
\hline Q Rovista Dialectus & Ano 4 & n. 10 & Janeiro - Julho 2017 & p. 150-168 \\
\hline
\end{tabular}
}


do redesenho curricular, e se consolida ao anunciar suas bases nas orientações contidas nas Diretrizes Curriculares Nacionais para a Educação Básica (DCN) instituídas por Resolução CEB/CNE, nº 2, em 30 de janeiro de 2012, onde estão definidas as diretrizes para o ensino médio. Como justificativa para as novas orientações curriculares para o ensino médio ressalta-se no texto das DCN (2013, p. 146) que "da forma como está organizado na maioria das escolas, o Ensino Médio não dá conta de todas as atribuições definidas na Lei de Diretrizes e Bases da Educação (LDB)" ${ }^{10}$, e recorre ao trabalho "Melhores Práticas em Ensino Médio no Brasil" (BID, 2010) para afirmar que a referida pesquisa demonstra possibilidades de que nas escolas públicas se desenvolvam excelentes trabalhos.

Ainda nesse percurso, a análise apresentada no documento para abrigar certo consenso quanto ao que propõe, recorre aos dados do $\mathrm{IBGE}^{11}$ de que quase metade dos adolescentes de 15 a 17 não está matriculada no Ensino Médio. Nesse sentido, alude-se á importância do Plano de Desenvolvimento da Educação (PDE), e a necessidade de consolidar-se o Sistema de Avaliação da Educação Básica (SAEB) e do Exame Nacional do Ensino Médio (ENEM), dentre outros, como referência as necessidades de melhoria do ensino. Os vínculos entre as decisões definidoras de políticas públicas em educação no contexto brasileiro recente e instituições privadas financiadoras as quais nos referimos antes tem se revelam na citação que segue:

\footnotetext{
O Plano de Desenvolvimento em Educação (PDE), concretizado por Estados e Municípios, por meio da estruturação da adesão ao Plano de Metas Compromisso Todos pela Educação e respectivos Planos de Ações Articuladas (PAR), conduz á revisão das políticas públicas de educação e potencializa a articulação de programas e ações educacionais do governo. (DCN, 2013, p. 147).
}

Nesse sentido, apresentamos a lógica que perpassa as políticas educacionais adotadas no Brasil desde os anos de 1990. O PNEM se estrutura e é implementado o programa de formação de professores em função das avaliações imbuído das avaliações externas e orientados pelas DCN.

É necessário ressaltar que tanto a LDB nº. 9.394/96 como as DCN (2013) foram formuladas sob o peso político e financeiro que representaram as orientações da Declaração de Jomtien (1990) para os países em desenvolvimento. No contexto de

\footnotetext{
${ }^{10}$ Lei n. 9.394/1996, MEC.

11 "Síntese dos Indicadores Sociais do IBGE: uma análise das condições de vida da população brasileira" (IBGE, 2010 apud DCN, 2013, p. 146).
}

\begin{tabular}{|c|c|c|c|c|}
\hline Revista Aidectus & Ano 4 & n. 10 & Janeiro - Julho 2017 & p. $150-168$ \\
\hline
\end{tabular}


reestruturação do Estado brasileiro a partir dos anos de 1990, sob uma contundente campanha para o consenso das premissas do neoliberalismo, impuseram a reorganização do sistema de ensino público. É importante destacar o alinhamento dessas propostas formativas com o ideário neoliberal presente nas políticas educacionais implantadas no Brasil a partir dos anos de 1990. Nesse cenário, a educação passou a ser compreendida pelos organismos multilaterais, especialmente o Banco Mundial, como uma forma de preparar os indivíduos para adaptar-se às necessidades mercadológicas do sistema capitalista.

O Estado Neoliberal, pautado na restrição ao financiamento de serviços como saúde e educação, sob o preceito regulador do mercado para gerir a sociabilidade entre indivíduos atribui o papel de controle à atividade educativa, por meio da reorientação dos métodos, conteúdos, e ações pedagógicas como formas de controle, favorecendo uma desvalorização do conhecimento teórico e um enaltecimento de experiências práticas individuais exitosas usadas como modelos a serem replicados desconsiderando o contexto social, político e econômico no qual a educação está inserida. Nesse contexto, os programas de formação de professores enfatizam técnicas e métodos para a ação docente em função da capacitação dos mesmos de pensarem soluções para problemas imediatos enfrentados na sala de aula, relativos às dificuldades dos alunos em apreenderem o conhecimento em seu sentido prático, instrumental.

Kuenzer (2005) nos alerta o quão é preocupante a facilidade com que a pedagogia orientada pela epistemologia da prática vem se apropriando, sob o auspício do capital, de concepções próprias da pedagogia crítico-dialética. Esse movimento teórico gera uma ambiguidade e uma dispersão dos conceitos frente às suas possibilidades de desvendar o real, imprimindo às ações com possibilidades emancipatórias um caráter alienante. Nesses termos, o trabalho do professor que no mais das vezes resta à margem das políticas de formação aparece fragmentado, tornando-se um obstáculo ao processo de reconhecimento do professor naquilo que ele realiza.

Para pensarmos a dimensão deste problema, uma rápida incursão nos conceitos orientadores dos programas de formação docente não é esforço vão para desvelarmos aspectos da realidade escondidos à sombra do ignoto.

O campo da formação de professores ao final do século XX viu chegar novos termos e conceitos referentes aos professores, sua formação e seu trabalho. Expressões como: epistemologia da prática, professor-reflexivo, prática-

\begin{tabular}{|l|l|l|l|l|}
\hline Revista Dialectus & Ano 4 & n. 10 & Janeiro - Julho 2017 & p. 150-168 \\
\hline
\end{tabular}


reflexiva, professor-pesquisador, saberes docentes, conhecimento e competência passaram a fazer parte do vocabulário corrente da área. (ALVES, 2007, p.265).

As críticas às orientações da epistemologia da prática já se acumulam. Ghedin (2012) afirma que a crítica segue à razão prática como fundamento dado à noção de reflexividade, de cunho positivista. Em contraposição a este postulado, o autor pondera:

[...] todo ser humana é dotado de reflexividade (...) As questões distintivas das diversas formas sociais de reflexão são simultâneas e anteriores ao próprio processo reflexivo. Este processo anterior e que marca radicalmente o resultado do conhecimento fundado na reflexividade situa-se por um lado, nas condições históricas e objetivas do sujeito que reflete e, por outro, diríamos, no trabalho, como ação fundante do humano e de sua condição. (Ghedin, 2012, p. 149).

A epistemologia da prática supõe que o exercício intelectual do professor lhe fornecerá suporte para a crítica, a autonomia e a emancipação. Todavia, ao restringir o exercício da crítica ao fazer pedagógico em sala de aula, com a proposta de "reflexãona-ação", recupera o paradigma tecnicista, "a prática é tomada em seu sentido de atividade, destituída de caráter teórico", aos professores são dadas as condições de refletir sobre sua prática “'pensando o que fazem, enquanto fazem', em situações de incerteza, singularidade e conflito" (Kuenzer, 2016, p. 9).

Nesse sentido, observa-se que os programas de formação se limitam, intencionalmente, ao campo da reflexão sobre a prática docente, compreendendo por prática a experiência do professor em sua atividade de trabalho.

No modelo adotado para formação continuada do professor, observa-se o foco na instrumentalização desse profissional para alcançar metas propostas por agentes externos materializadas em avaliações externas e na utilização de uma abordagem que valoriza a prática e a reflexão sobre a mesma, relegando ao segundo plano o referencial teórico e contextualização histórica, econômica e social da educação.

Segundo Duarte (2010), nas duas últimas décadas, o debate educacional tem se caracterizado por uma quase total hegemonia das "pedagogias do aprender a aprender", com destaque para o construtivismo, a pedagogia do professor reflexivo, a pedagogia das competências, a pedagogia dos projetos e a pedagogia multiculturalista. De acordo com este autor, a perspectiva do professor-reflexivo é a aplicação das Pedagogias do Aprender a Aprender na formação de professores, pois o conhecimento que deve ser considerado pelo professor, nessa abordagem, nas decisões relativas à sua atividade profissional é o conhecimento tácito.

\begin{tabular}{|l|l|l|l|l|}
\hline Q Povista Dialectus & Ano 4 & n. 10 & Janeiro - Julho 2017 & p. 150-168 \\
\hline
\end{tabular}


Nas atividades que observamos nos programas de formação continuada da educação básica da rede pública municipal ${ }^{12}$ e estadual a estrutura dos encontros evidencia o caráter instrumental dessas formações, na medida em que focam o desenvolvimento de atividades que visem ao êxito dos alunos em avaliações externas. São realizadas oficinas com os professores a partir da demanda dos alunos, tendo como referência o resultado da avaliação municipal. Aos professores é dada a tarefa de sanar, na sala de aula, as dificuldades dos descritores evidenciadas pelos alunos na avaliação, visando melhoria para a avaliação seguinte.

Dessa forma, o professor é condicionado a reduzir o seu processo formativo a reflexão de atividades práticas de sala de aula e a limitar os conteúdos curriculares à matriz de referência das provas estandardizadas. O efeito dos processos de formação em relação direta com sua finalidade, relativa à melhoria da aprendizagem do aluno avaliado, atinge o professor na sua individualidade, pois este aparece como profissional responsável pelo "fracasso escolar" do aluno. As formações são fundamentalmente estruturadas na reflexão sobre a prática do professor objetivando a instrumentalização de técnicas para o êxito nessas avaliações.

A ênfase na apresentação de técnicas que objetivam elevar o desempenho dos alunos em avaliações externas converge com a perspectiva de que as políticas públicas em educação no país, dentre outros elementos, enfatizam aspectos como a descentralização, a formação de indivíduos flexíveis, a busca por resultados, a bonificação, a formação de um ser competitivo, dentre outros, relacionados ao viés empresarial. Uma questão preocupante é a naturalização dos efeitos dessas políticas.

Esses profissionais, devido à estruturação do sistema de ensino, passam a desempenhar o papel de executores de demandas educacionais que corroboram para uma sociedade de classes que mantém a desigualdade de acesso ao conhecimento, destinando aos filhos dos trabalhadores, uma escola limitada à instrumentalização para o mercado capitalista. A naturalização se revela também nos próprios processos formativos quando nos programas não comparece questionamento algum acerca da realidade social em que se insere a ação educativa, a escola e o professor. As competências e habilidades a serem tratadas como foco e objetivo da formação sequer

\footnotetext{
${ }^{12}$ Referimo-nos ao Sistema Municipal de Avaliação do Ensino Fundamental (SMAEF), do município de Russas-CE, que avalia os alunos do $3^{\circ}$ ano ao $9^{\circ}$ ano, nas disciplinas de Língua Portuguesa e Matemática, bimestralmente partindo da proposta curricular de cada ano com foco na Matriz de Referência da Prova Brasil.
}

\begin{tabular}{|l|l|l|l|l|}
\hline Q Povista Dialectus & Ano 4 & n. 10 & Janeiro - Julho 2017 & p. 150-168 \\
\hline
\end{tabular}


aludem a uma sociedade cujas diferenças emanam em uma situação de desigualdade. Conforme atesta Torres (2003):

O modelo educativo que nos propõe o BM (Banco Mundial) é um modelo essencialmente escolar e um modelo escolar com duas grandes ausências: os professores e a pedagogia. Um modelo escolar configurado em torno de variáveis observáveis e quantificáveis, e que não comporta os aspectos especificamente qualitativos, ou seja, aqueles que não podem ser medidos, mas que constituem, porém, a essência da educação. (Torres, 2003, p. 139).

Assim, os programas de formação continuada de professores vigentes no cenário da educação básica, baseiam-se na perspectiva da "epistemologia da prática", destacando-se nesse processo formativo a abordagem de procedimentos de ensino, roteiros e esquemas para orientar a prática, situações de resolução de problemas diários do cotidiano escolar, modelos de conhecimentos práticos erigidos das interações em sala de aula, dentre outros aspectos, que colabora para construção de um perfil de professor ligado ao praticismo, ao individualismo, à banalização da teoria e ao pragmatismo.

Dessa forma, o professor é, intencionalmente, limitado a refletir apenas o contexto de sala de aula, sendo impossibilitado de perceber que as problemáticas escolares fazem parte de um contexto mais amplo e complexo. Por esse motivo, muitas vezes, esse profissional assume uma responsabilidade que não decorre de sua atuação, mas do lugar ocupado pela instituição escolar em uma sociedade de classes. Dessa forma, é válido questionar, até que ponto os programas de formação de professores estão realmente vinculados a um processo de formação do pensamento crítico do professor.

\section{A formação do professor para além do capital: a construção da crítica}

O modelo de formação no qual o professor está imerso, prende-o em uma estrutura fechada que o impede de entender a realidade na qual o conhecimento está sendo construído. Isso porque a formação, seja inicial ou continuada, trabalha com o conhecimento em um contexto que ignora sua construção social e histórica, diferentemente do método desenvolvido por Marx (2016), que supera o dualismo entre sujeito e objeto na construção do conhecimento, pois advoga a existência de uma

\begin{tabular}{|l|l|l|l|l|}
\hline Q Rovista Dialectus & Ano 4 & n. 10 & Janeiro - Julho 2017 & p. 150-168 \\
\hline
\end{tabular}


relação histórica, dialética e reflexiva entre o sujeito que busca conhecer e o objeto que é conhecido, isto é, entre a consciência e a realidade objetiva.

O conhecimento não está limitado à prática imediata, esta é ponto de partida como experiência sensível que atribui ao sujeito que conhece a tarefa de decompor os elementos que a constituem. Assim, “conhecemos o mundo, as coisas, os processos somente na medida em que 'criamos', isto é, na medida em que os reproduzimos espiritualmente e intelectualmente" (Kosik, 1989, p. 206).

Nesse sentido, o conhecimento configura-se como uma atividade resultante da relação do homem com o mundo, a partir da satisfação de suas necessidades. Nesse processo, o homem, enquanto ser teleológico utiliza o trabalho - ação mediadora e criadora, de acordo com suas intencionalidades, materializando novos elementos que integrarão as atividades futuras. Esses elementos novos, que surgem do trabalho do homem, representam um grau de conhecimento da natureza por este, transformando-se em um conhecimento cada vez mais elaborado e de acordo com suas necessidades. Assim,

Esse conhecimento, apropriado pelo sujeito, passa a ser incorporado à vida e servirá de base para outras atividades. Ao agir sobre o mundo, os homens o vão conhecendo, transformando-o e, ao mesmo tempo, transformando-se. Assim, a vida social vai se efetuando como processo histórico - construído e não como dado imediato imposto pela natureza. (Araújo, 2003, p. 261).

No processo de conhecimento, o homem, portanto, transforma o mundo e por ele é transformado, em um movimento marcado pela historicidade, a qual só reconhece o homem enquanto um ser ativo, dentro de uma sociedade, visto como um sujeito real, em uma realidade objetiva, concreta e material. Assim, a historicidade, consequentemente, é processual, construída e objetivada. Nesse ínterim, o objeto do conhecimento é a realidade em que o sujeito está inserido, uma realidade histórica, em construção e concreta, que se apresenta ao sujeito de modo caótico, marcada por determinações múltiplas e complexas. Em vista disso, a historicidade compõe a vida humana, em sua objetivação no mundo, como uma dimensão ontológica do ser social. Todo conhecimento encontra-se imbuído de historicidade posto que resulta da relação homem-mundo, o sujeito e o objeto, numa relação dialética.

A categoria da historicidade revela-se como uma dimensão da práxis na medida em que a práxis é um modo próprio do ser do homem e se produz historicamente. Esclarece Kosik (1989):

\begin{tabular}{|l|l|l|l|l|}
\hline Q Rovista Dialectus & Ano 4 & n. 10 & Janeiro - Julho 2017 & p. 150-168 \\
\hline
\end{tabular}


A praxis é ativa, é atividade que se produz historicamente - quer dizer, que se renova continuamente e se constitui praticamente -, unidade do homem e do mundo, da matéria e do espírito, de sujeito e objeto, do produto e da produtividade. Como a realidade humano-social é criada pela praxis, a história se apresenta como um processo prático no curso do qual o humano se distingue do não-humano: o que é humano e o que não é humano não são já predeterminados; são determinados na história mediante uma diferenciação prática. (...) A praxis se articula com todo o homem e o determina na sua totalidade. (Kosik, 1989, p. 202, grifos do autor).

Nesse sentido, Kuenzer (2016) reflete sobre a dimensão presentista da história definida na epistemologia da prática carece ser denunciada. Reduzir o ato reflexivo à dimensão do presente como referência à produção do conhecimento sobre ele é esvaziar a "experiência histórica" substituindo-a pela "experiência do momento". Nessa perspectiva, não há história e, por conseguinte, não há futuro. Os conflitos e os desafios próprios da relação pedagógica passam a ser um atributo do indivíduo, e não da história enquanto totalidade. Nega-se assim toda e qualquer possibilidade de transformação, uma vez que o sujeito que age encontra-se encurralado num relativismo subjetivo do qual depende toda sua existência, perdendo a referência na coletividade, na comunidade.

Nega-se, em tais circunstâncias, a possibilidade das práticas emancipatórias, e comumente o professor toma para si, individualmente, a responsabilidade de todo o processo de ensino e aprendizagem, pois as relações sociais, a relação da escola com a sociedade, aparece como resultante de escolhas individuais. Nesse modo de ler o sentido da ação pedagógica destitui-se dos processos formativos a noção de formação como práxis, ou seja, como uma atividade intencional, transformadora, emancipatória, própria do ser do homem na sua historicidade.

Como o professor pode se reconhecer como um ser da práxis, na sua ação pedagógica, se não lhes são dados os fundamentos de uma teoria do conhecimento desveladora do movimento da história, como objetivação do homem no mundo? Em que medida, sob os fundamentos da reflexividade dados pela epistemologia da prática, o professor encontra o sentido de sua ação pedagógica? São indagações que felizmente possuem algumas respostas que apontam para possibilidades emancipatórias se consideramos a realidade como contraditória na sua essência histórica.

É interessante perceber no Parecer $n^{\circ}$ 5/2011, publicado nas DCN (2013) a referência feita ao perfil do professor a ser formado nas circunstâncias das novas orientações educacionais vigentes.

\begin{tabular}{|l|l|l|l|l|}
\hline Q Rovista Dialectus & Ano 4 & n. 10 & Janeiro - Julho 2017 & p. 150-168 \\
\hline
\end{tabular}


Exige-se do professor que seja capaz de articular os diferentes saberes escolares à prática social e ao desenvolvimento de competências para o mundo do trabalho. Em outras palavras, a vida na escola e o trabalho do professor tornam-se cada vez mais complexos. (...) é necessário repensar a formação dos professores para que possam enfrentar as novas e diversificadas tarefas que lhes são confiadas na sala de aula e além dela. (DCN, 2013. P. 171).

Do ponto de vista da divisão do trabalho na escola e do tempo que o professor dispõe para realizar as atividades que dele se exige, ou se espera, podemos afirmar que a articulação entre saberes escolares e prática social requer do professor maior tempo de estudo se considerarmos o ato de refletir como um ato de pesquisa. $\mathrm{O}$ espaço e o tempo de que dispõe o professor no seu cotidiano de trabalho, consideradas as devidas condições do sistema educacional brasileiro, nos parece insuficiente e muitas vezes inapropriado para a atividade do pensamento. Soma-se a isso o novo paradigma do conhecimento que difere de sua formação inicial no que se refere ao processo de produção do conhecimento. O que são os "diferentes saberes escolares”? É necessário esclarecer, como o faz Duarte (2010) que a epistemologia da prática reconhece como saberes o conhecimento que os professores utilizam realmente no seu trabalho cotidiano na escola e na sala de aula. Nesse sentido, os processos formativos devem se municiar da investigação sobre quais saberes são esses, pois se supõe que são distintos dos conhecimentos transmitidos no âmbito da formação acadêmica, universitária.

Como observamos, a atividade docente se identifica pela atividade intelectual e a teoria é um componente da prática reflexiva. Tomar a sociedade burguesa moderna como uma totalidade é pré-requisito para que se entenda como o conhecimento é construído, uma vez que este está diretamente ligado às relações socioeconômicas que são estabelecidas entre os indivíduos, através da acumulação de riquezas, em que muitos são explorados e poucos a têm em suas mãos. É através da totalidade que se chega ao real, pois este "é uma síntese de muitos complexos, muitas mediações e relações, e que, para conhecê-lo, é necessário considerar essa sua complexidade que compõe uma unidade, uma totalidade [...] uma síntese de muitos processos" (Araújo, 2003, p. 263). Assim, entendendo o homem como um ser imerso em uma realidade social, pode-se afirmar que ele é um complexo e, também, representa uma totalidade em desenvolvimento.

Outras duas categorias importantes para se compreender como o conhecimento é construído, a partir do método de Marx, na sua elaboração do conceito de crítica, são a

\begin{tabular}{|l|l|l|l|l|}
\hline Q Rovista Dialectus & Ano 4 & n. 10 & Janeiro - Julho 2017 & p. 150-168 \\
\hline
\end{tabular}




\section{Lúcia Helena de Brito/ Lydyane Maria Pinheiro de Lima / Sirneto Vicente da Silva}

contradição e a mediação. Ambas estão intimamente ligadas à totalidade e à historicidade. Para Marx (2016), a contradição é imanente à realidade, na sua concreticidade. A contradição evidencia-se no movimento de intervenção do homem na natureza e na história, no processo de humanização do mundo. A transformação gestada nessa relação caracteriza o movimento da história, como demonstra Marx (2016) ao elaborar a crítica da economia política, na medida em que pergunta pela criação do conflito, no contexto da sociedade capitalista. A radicalidade de sua crítica não possui outro sentido se não a busca por desvendar as mediações das relações entre as coisas, na sua objetividade e na sua essência histórica.

A mediação "pode ser compreendida como as diversas conexões que se efetivam entre os processos sociais (complexos sociais) enquanto relações reflexivas" (Araújo, 2003, p. 264), dentro da totalidade. Assim, a sociedade burguesa, enquanto totalidade concreta, é articulada por mediações internas e externas que constituem as relações de interdependência das esferas que compõem as relações sociais, através das quais o conhecimento vai sendo construído.

Conclui-se, por conseguinte, que o novo conhecimento é construído a partir das contradições existentes na sociedade, as quais necessariamente negam o "velho" conhecimento rompendo com esse conhecimento e ao mesmo tempo dando-lhe continuidade, dentro de uma nova realidade que compõe a totalidade. Logo, a contradição, enquanto princípio básico do movimento transita entre a tese, a antítese e a síntese. É nesse movimento que o conhecimento vai sendo construído.

No tocante à formação de professores, seja a inicial ou continuada, faz-se necessário, reconhecer que o conhecimento se apresenta como sendo uma informação que é repassada, sem que se questione ou se entenda o porquê de tal conhecimento tornar-se relevante e, portanto, deve fazer parte do processo de ensino e aprendizagem. $\mathrm{Na}$ verdade, o que se percebe é que há um conjunto de conteúdos escolhidos por "especialistas" para serem ministrados aos professores e, como extensão, aos alunos. Percebe-se, assim, que os conteúdos são aprendidos e ensinados como o cumprimento de um projeto que descarta a criticidade, bem como a aprendizagem que deve voltar-se para a transformação social.

Para o método de Marx, o conhecimento é fundamental para o desenvolvimento histórico da humanidade. Por isso, o método por ele desenvolvido parte do real e volta para o real, sempre entendendo o conhecimento como uma

\begin{tabular}{|l|l|l|l|l|}
\hline Q Rovista Dialectus & Ano 4 & n. 10 & Janeiro - Julho 2017 & p. 150-168 \\
\hline
\end{tabular}


construção histórica, portanto dialética no intercâmbio entre o sujeito e o objeto de conhecimento. Em relação ao método que desenvolveu, Marx (2016, p. 247) postula:

\begin{abstract}
[...] o melhor método será começar pelo real e pelo concreto, que são a condição prévia e efetiva; assim, em economia política, por exemplo, começar-se-ia pela população, que é a base e o sujeito do ato social de produção como um todo. [...] se começássemos pela população teríamos uma visão caótica do todo, e através de uma determinação mais precisa, através de uma análise, chegaríamos a conceitos cada vez mais simples; do concreto figurado passaríamos a abstrações cada vez mais delicadas até atingirmos as determinações mais simples. Partindo daqui, seria necessário caminhar em sentido contrário até chegar finalmente de novo à população, que não seria desta vez a representação caótica de um todo, mas uma rica totalidade de determinações e de relações numerosas. (Marx, 2016, p. 247).
\end{abstract}

Marx, portanto, advoga que o conhecimento tem como ponto de partida e de chegada a realidade concreta, partindo-se das determinações mais simples, para se desvendar a realidade caótica como se apresenta e voltando para as mesmas determinações, agora compreendidas em sua totalidade, observando-se as diversas determinações. Assim, deve-se, partindo da aparência do objeto do conhecimento, perseguir e conhecer a essência, para que se chegue ao conhecimento concreto do objeto. Em suma, reconhecendo que a realidade é composta por múltiplas determinações, parte-se do real caótico, fazendo o caminho de ida, a partir da construção de categorias que fazem parte dos múltiplos complexos presentes na realidade, confrontando essas categorias com o próprio real para fazer o caminho de volta, na busca de compreender a realidade a partir das relações sobre as quais o real está posto. Assim, chega-se à síntese, isto é, ao real concreto não mais caótico, mas pensado e conhecido em sua totalidade.

Entender e utilizar o método construído por Marx no processo de ensino e aprendizagem com vistas à construção do conhecimento propicia ao professor pensar sua práxis dialeticamente. Isso implica em uma postura investigativa, que inclui a clareza de que o conhecimento científico é tocado por ideologias as quais, na maioria das vezes, são sedutoras e conseguem se inculcar nas práticas de ensino e aprendizagem de modo naturalizado. Cabe, portanto, reconhecer a escola como lugar privilegiado para a construção do conhecimento historicamente acumulado pela humanidade, a qual está imersa em uma realidade composta por múltiplas determinações. Nesse contexto, tornase fundamental entender a função social que o conhecimento assume para a transformação ou reprodução das relações de dominação estabelecidas na sociedade capitalista.

\begin{tabular}{|l|l|l|l|l|}
\hline Q Rovista Dialectus & Ano 4 & n. 10 & Janeiro - Julho 2017 & p. 150-168 \\
\hline
\end{tabular}




\section{Considerações finais}

Imerso na dinâmica da divisão do trabalho a qual se submete o professor dada a organização do sistema educacional brasileiro, as novas diretrizes que orientam a aquisição de "habilidades" e "competências" geram no professor um sentimento de impotência diante da mudança que precisam efetuar em seu modo de viver, de pensar e de sentir a realidade, uma vez que lhes são apresentados novos métodos de trabalho para os quais muitas vezes não encontram meios de realiza-los nem tempo para compreendêlos na sua relação com a realidade mais ampla.

A fragmentação do trabalho e atinge o coração da atividade docente ao dissociar o saber teórico do professor da sua atividade prática, que no mais das vezes se manifesta no comportamento passivo assimilado durante anos de trabalho. A realidade de classes no contexto do capitalismo aparece naturalizada quando se institui ao processo formativo o objetivo de adequação do ensino à realidade dos alunos e à sua preparação para o ingresso no mundo do trabalho, diga-se, no mercado de trabalho.

Kuenzer (2005) compreende a superação dos limites dados pela fragmentação do trabalho considerando a categoria da contradição, que permite o entendimento da dinâmica do movimento do real, e assim coloca o sujeito ativamente como ser da práxis, uma vez conscientes do seu agir no mundo. Pois somente a consciência sobre a intencionalidade de sua ação, o sujeito, na sua experiência existencial, pode superar as relações de dominação, muitas vezes mediada pela técnica e pela manipulação do seu fazer-se no mundo. Assim também se processa na vida cotidiana do professor e somente por meio da luta por emancipação se supera as condições históricas e sociais consubstanciadas no modo concreto na sociedade de classes.

Salienta-se que as formações atendem às demandas preestabelecidas pelas secretarias da educação, centradas na gestão por resultados e na epistemologia da prática, desconsiderando o contexto sócio-político-econômico em que essas práticas se desenvolvem; e que a historicidade, a totalidade, a contradição e a mediação, princípios do método de Marx (2016), possibilitam a formação do pensamento político dos docentes, interferindo em sua postura frente à realidade.

O modelo hegemônico de ensino das escolas advém de um projeto de educação formulado com o intuito de manter as relações de classe na sociedade capitalista. Para tanto, são desenvolvidas políticas públicas, de modo mais intensificado a partir da

\begin{tabular}{|l|l|l|l|l|}
\hline Q Rovista Dialectus & Ano 4 & n. 10 & Janeiro - Julho 2017 & p. 150-168 \\
\hline
\end{tabular}




\section{Lúcia Helena de Brito/ Lydyane Maria Pinheiro de Lima / Sirneto Vicente da Silva}

década de 1990, modeladoras da prática educativa do professor por meio de uma formação que tem como centro o modelo de gestão por resultados e da reflexão sobre a prática.

Dessa forma, tais políticas públicas educacionais, limitam a práxis do professor ao ambiente mais específico da sala de aula, desarticulando a educação do contexto social, político e econômico no qual está intrinsecamente inserida. Em contrapartida, o método de Marx (2016) possibilita a análise da realidade por professores e estudantes, uma vez que está fundado nos princípios da historicidade, totalidade, contradição e mediação. Como afirma Kosik (1989),

\footnotetext{
Assim, a praxis compreende - além do seu momento laborativo - também o seu momento existencial: ela se manifesta tanto na atividade objetiva do homem, que transforma a natureza e marca com sentido humano os materiais naturais, como na formação da subjetividade humana, na qual os momentos existenciais como a angústia, a náusea, o medo, a alegria, o riso, a esperança, etc., não se apresentam como 'experiência' passiva, mas como parte da luta por reconhecimento, isto é, do processo de realização da liberdade humana. (Kosik, 1989, p. 204, grifos do autor).
}

Por conseguinte, esses princípios são fundamentais para a construção de uma educação pautada na transmissão dos conteúdos historicamente acumulados pela humanidade, como forma de acesso da classe trabalhadora, possibilitando a formação de um pensamento de transformação social, pois interferem na organização do pensamento político do professor e na sua postura em relação a sua concepção de educação.

Sabe-se, portanto, que o sistema educacional está estruturado de modo que força os professores a manterem uma atuação mínima, isto é, voltada apenas para o ensino dos conteúdos mínimos cobrados nas avaliações externas, por exemplo. Além disso, elementos externos à escola interferem no processo educacional e dificultam a existência de uma prática comprometida com a emancipação como função social da escola. Por outro lado, o desenvolvimento de uma práxis crítica possibilita, embora lentamente, a transformação da realidade.

\section{Referências Bibliográficas}

ALVES, W. F. A formação de professores e as teorias do saber docente: contextos, dúvidas e desafios. Educação e Pesquisa, São Paulo, v. 33, n. 2, p. 263-280, maio/ago. 2007.

ARAÚJO, L. B. de C. A questão do método em Marx e Lukács: o desafio da reprodução ideal de um processo real. In: MENEZES, A. M. D. (Org.). Trabalho,

\begin{tabular}{|l|l|l|l|l|}
\hline Q Rovista Dialectus & Ano 4 & n. 10 & Janeiro - Julho 2017 & p. 150-168 \\
\hline
\end{tabular}


Lúcia Helena de Brito/ Lydyane Maria Pinheiro de Lima / Sirneto Vicente da Silva

sociabilidade e educação: uma crítica à ordem do capital. Fortaleza: Editora UFC, 2003.

DUARTE, N. O debate contemporâneo das teorias pedagógicas. In: MARTINS, L. M.; DUARTE, N. (Org.). Formação de Professores: limites contemporâneos e alternativas necessárias. São Paulo: Cultura Acadêmica, 2010.

GHEDIN, E. Professor reflexivo: da alienação à autonomia da crítica. In: PIMENTA, S. G., GHEDIN, E. (Org.). Professor reflexivo no Brasil: gênese e crítica de um conceito. $7^{\mathrm{a}}$ ed. São Paulo: Cortez, 2012.

KOSIK, K. Dialética do concreto. Tradução de Célia Neves e Alderico Toríbio. $5^{\mathrm{a}}$ ed. Rio de Janeiro: Paz e Terra, 1989.

KUENZER, A. Z. Exclusão includente e inclusão excludente: a nova forma de dualidade estrutural que objetiva as novas relações entre educação e trabalho. In: Lombardi, J.; Saviani, D.; Sanfelice, J. (Org.). Capitalismo, trabalho e educação. 3. ed. São Paulo: Autores Associados; histedbr, 2005. p. 77-96.

Trabalho e escola: a aprendizagem flexibilizada. In: XI Reunião Científica Regional da Anped Sul, 2016, Curitiba. Educação, movimentos sociais e políticas governamentais, 2016. p. 1-22

MARX, K. Manuscritos económico-filosóficos. Tradução de Artur Morão. Lisboa, Portugal: Edições 70 Lda, 1993.

Contribuições à crítica da economia política. Tradução: Maria Helena Barreiro. $5^{\text {a }}$. ed. - São Paulo: Editora WMF Martins Fontes, 2016. (Clássicos WMF)

SOUSA JÚNIOR, Justino de. A crise da escola. Fortaleza: Imprensa Universitária, 2014. 288 p. (Estudos da Pós-Graduação)

\begin{tabular}{|l|l|l|l|l|}
\hline Q Rovista Dialectus & Ano 4 & n. 10 & Janeiro - Julho 2017 & p. 150-168 \\
\hline
\end{tabular}

